\title{
La adaptación de la revista VOGUE al nuevo contexto digital del periodismo de moda
}

\section{VOGUE magazine adaptation to the new digital context of fashion}

journalism

Carmen Cristófol Rodríguez. Universidad de Málaga (carcrir@uma.es)

Francisco Cabezuelo Lorenzo. Universidad Complutense de Madrid (fcabezuelo@ucm.es)

Francisco Javier Paniagua Rojano. Universidad de Málaga (fjpaniagua@uma.es)

Recibido: 10/09/2016 - Aceptado: 3/04/2017

Resumen:

El presente trabajo analiza la adaptación al contexto digital de la revista Vogue, como paradigma del periodismo de moda, teniendo en cuenta la influencia que esta publicación ejerce sobre dicho sector. Tras una introducción contextual de las revistas femeninas, se examina Vogue como icono en su sector para posteriormente llevar a cabo el análisis de contenido de su web a través de las siguientes variables: audiencia, secciones principales, tipo de estructura, presencia de sus editoras en portada, formatos publicitarios, mecanismos de promoción en redes, distribución de los contenidos principales (moda y belleza), tipo y número de interactividad con las lectoras y uso del brand placement con las marcas selectas. Como principal conclusión, se puede decir que Internet se ha convertido en una herramienta aliada de las revistas de moda y que las redes sociales han resultado ser una gran oportunidad, si bien surgen ahora nuevos retos. En el caso de Vogue, cabe destacar que la revista ha ampliado su audiencia no solo cuantitativamente, sino también en nuevos perfiles, como por ejemplo la cobertura de una nueva franja de edad más joven.

Palabras clave:

Periodismo de moda; digital; Vogue; brand placement; publicidad.

\section{Abstract:}

This research analyzes how Vogue, as a paradigm of fashion journalism, has been adapting to the new digital context, according to the strong influence that it has on this journalist area. After a contextual introduction to the field of women's magazines, this articles analyses the case of Vogue as an icon. Then, the research analyzes the web content through the following variables: target audience, main sections, type of structure, presence of its editors on the cover, advertising formats, mechanisms of promotion in social media, distribution of the main content (fashion and beauty), type and number of interactivity with readers and use of brand placement with selected brands. The research concludes that Internet has become a key allied of fashion magazines and social media has turned in a great opportunity. However, this sector of the journalistic industry must face new challenges. In the specific case of Vogue, it must be underlined that, thanks to the digital tools, this magazine has expanded its audience not only quantitatively, but also in new profiles, such as a younger audience.

\section{Keywords:}

Fashion journalism; digital; Vogue; brand placement; advertising. 


\section{Introducción, justificación y contexto}

Los orígenes de la denominada "prensa femenina", término hoy ya casi en desuso excepto en algunos manuales de periodismo frente al actual término de "información especializada en moda y tendencias", se remontan a 1663. Ese año apareció en Londres la publicación semanal Lady Mercury, considerada la primera publicación moderna destinada solo a un público eminentemente femenino. En el caso de España, los antecedentes históricos más reseñables de este tipo de publicaciones fueron las revistas La Moda Elegante y El Correo de las Damas en el siglo XIX (González Díez \& Pérez Cuadrado, 2009: 53).

Cuestiones domésticas, de estética, ocio y entretenimiento dominaban aquellas publicaciones en sus orígenes. Como en la mayoría de las cabeceras destinadas al público femenino, los títulos de las secciones hacían referencias a nombres y palabras propias del ámbito doméstico de la mujer del momento, lo que ya indicaba desde un principio claramente a quien iban dirigidas (Buitoni, 1990:7). En parte, también sigue siendo hoy así. Sin embargo, el actual escenario social y mediático es hoy totalmente diferente y las revistas femeninas tienen hoy muchos más contenidos adaptados a la mujer del siglo XXI que busca avances en la igualdad de derechos y oportunidades con el hombre.

En este mismo contexto, Zygmunt Bauman (2010) nos recuerda que la actual sociedad tiene un auténtico protagonista: el consumo que parece invadirlo todo. El mundo de las compras y la moda están omnipresentes. El consumo, la imagen y la recreación de estilos de vida a través de la compra de productos o contratación de servicios han servido a muchos autores incluso para hacer estudios centrados en la generación de identidades sociales tanto en el caso de la mujer (Roach-Higgins y Eicher, 1992: 19-45; Johnson, Schofield y Yurchisin, 2002: 125-137; Guiry, Magi y Lutz, 2006: 74-83) como en el caso del hombre, sobre todo en su esfera profesional (Peluchette, Karl y Rust, 2006: 45-63; Kang, Sklar y Johnson, 2011: 412-427).

El mundo de la moda y todo lo que la rodea ha generado su propio campo de especialización en el ámbito de la sociología (Smith, 2012), su propia ciencia casi ontológica (Kawamura, 2005) e incluso múltiples teorías psicológicas (Stryker y Burke, 2000). Moda, sociedad de consumo e industria de la comunicación, sobre todo en el caso de la publicidad, son vasos comunicantes. La publicidad "conforma un discurso ideológico que propone pautas de vida” (García López, 2016: 25). Ante estas realidades propias de la sociedad de masas, la publicidad que menospreciaba a la mujer y el hiperconsumo se han levantado desde hace ya tiempo voces críticas en defensa de la dignidad de la mujer ante la imagen que se ofrecía de ellas en este tipo de prensa tanto en investigaciones internacionales (Foucault, 1989) como nacionales (Gallego Ayala, 1990).

En este contexto, en las actuales sociedades occidentales, la prensa femenina, al igual que todo el periodismo, asiste a una transformación en la forma de comunicar de los medios sobre todo por la revolución digital que ha resultado del desarrollo de las nuevas tecnologías. La revolución digital ha cambiado nuestras vidas y ha generado un volumen de in- 
formación impensable hasta hace poco y que nunca antes se había dado. La democratización de la tecnología y de los nuevos dispositivos "ha propiciado la aparición de un usuario permanentemente conectado" (Costa Sánchez y Piñeiro Otero, 2013:27). La consecuencia es que los medios informativos se han visto obligados a innovar y reinventarse independientemente del sector de especialización informativa del que forman parte. Estos cambios han afectado a empresas de todo tipo, independientemente del objeto de negocio de una empresa. El entorno comunicativo ha cambiado "en casi todas sus dimensiones: tecnológica, modelos económicos, formas de producción, acceso, recepción y uso de los contenidos" (De Aguilera Moyano, 2014: 01). Así, Internet se ha presentado como "reflejo y metáfora de la velocidad inherente a la era contemporánea” (Rueda Laffond, Galán Fajardo y Rubio Moraga, 2014: 208).

Javier Díaz Noci explica todo este nuevo entorno con el término “convergencia”, utilizado previamente en comunicación por Ithiel de Sola Pool, Henry Jenkins o Ramón Salaverría. La convergencia ha afectado a diversos aspectos de la comunicación y desde una perspectiva técnica "supone una mayor portabilidad de los datos, la existencia de redes descentralizadas, una abundancia de tecnología y aplicaciones, el acercamiento de los procesos de creación y producción de que los usuarios se conviertan en productores y la aceleración del tiempo y los límites temporales" según Díaz Noci, (2010:562), quien también estima, desde un punto de vista organizativo, que "se detecta una tendencia de los medios hacia la producción integrada, los profesionales multitarea, la distribución multiplataforma y la audiencia activa.”

Han surgido nuevos formatos, nuevas secciones y contenidos, incluso nuevos roles profesionales y este cambio es especialmente notorio en la información especializada, entendida como la divulgación del conocimiento (Fernández del Moral, 2004), especialmente en el ámbito de la moda, estilo, belleza y tendencias. Surgen nuevos formatos y también nuevos perfiles profesionales para atender esta demanda. Es por tanto necesario que los nuevos egresados se especialicen.

Una de estas nuevas áreas de especialización parece ser el mundo de la moda, que se ha convertido en una de las industrias más dinámicas. Es uno de los sectores que más interés despierta y, sobre todo, que proyecta una excelente imagen de España. Cada vez son más las marcas españolas que se hacen eco en las más prestigiosas pasarelas de todo el mundo.

España ha conseguido vender su producción textil a más de setenta países repartidos en los cinco continentes. Algunas firmas españolas, como Inditex (Zara, Pull \& Bear, Massimo Dutti, Stradivarius, Bershka, Oysho), Punto Fa (Mango), Cortefiel (Women'secret, Springfield), Adolfo Domínguez, Custo Barcelona, Caramelo, Desigual, Hoss Intropía, Armand Basi, o Amaya Arzuaga en moda mujer, Mayoral, Tutto Picolo o Neck \& Neck en moda infantil, Pronovias o Rosa Clará, en moda nupcial, Andrés Sardá o TCN en moda íntima están hoy presentes en todo el mundo (Alanís Muñoz, Cabezuelo Lorenzo y Fanjul Peyró, 2015: 314).

Según el estudio titulado 'El sector textil y el gasto en prendas de vestir 2015'publicado por EAE Business School, el mercado textil español crece hasta superar los 23.600 millones de facturación, un 0,68\% más respecto al año 2013. En España hay 
7.854 empresas dedicadas a la producción textil, un 3\% menos que en 2013 y un 45\% menos si se compara con el número de empresas que había en 2004. Sin embargo, la tendencia es positiva según Marta Riera, investigadora del Strategic Research Center de EAE. "El consumo de los españoles en prendas de vestir se ha visto disminuido en su participación del presupuesto familiar, mayormente por la situación económica que atraviesa el país desde 2008”, afirma Riera (2015).

Sin embargo, en el mismo informe se puede observar que la tendencia augura que, en los próximos cinco años, "el sector textil en España habrá sido capaz de recuperarse hasta alcanzar el volumen de negocio previo al estallido de la crisis" (Riera, 2015). En el mismo informe, dentro de las conclusiones, también se hace referencia a la tendencia positiva en la evolución reciente del mercado de la moda en España. En 2019 se calcula que subirá el gasto en ropa en nuestro país hasta los 26.137 millones de euros, un incremento del 10,6\% respecto a las cifras actuales. El gasto medio por español crecerá hasta los $567 €$, según los datos de la industria de la moda española. Manejando estas cifras y teniendo en cuenta que las empresas de nuestro país exportan actualmente a más de setenta países repartidos por todo el mundo podemos afirmar que la especialización en moda y belleza es una salida profesional que los jóvenes egresados deben tener en cuenta.

En el año 2016, las revistas del sector parecen haber sobrevivido a la crisis. Entre 2008 y 2013 el mercado de la comunicación sufrió como nunca, sobre todo la caída de la inversión publicitaria en medios convencionales, lo que provocó una crisis sin precedentes en el sector (Cabezuelo Lorenzo, 2013: 703-715). Sin embargo, en ese mismo año, la directora de la edición española de Vogue afirmaba en una entrevista que en su redacción se estaba viviendo "una de las épocas más fructíferas de la revista" (El Publicista, 2013: 20-23). A día de hoy, el sector parece gozar de buena salud y ser optimista ante los retos cercanos del sector. En la actualidad, en el conjunto de España se editan versiones nacionales de cabeceras internacionales de varias publicaciones del sector de la moda como Vogue, Elle, Cosmopolitan, Woman, Vanity Fair, Harper's Baazar, Glamour, Grazia y Marie Claire, entre otras. Por otro lado, están las publicaciones nacionales como Telva, S-Moda o Yo Dona, que son revistas con alta aceptación popular y que están ligadas a grupos editores españoles (González Díez, 2011: 15-30).

Tal y como resume Ganzabal Learreta (2007: 71) ya en 1996 y en 1997 revistas como Elle y Cosmopolitan sacaban sus ediciones online, a pesar de que ello "significaba pérdidas prácticamente aseguradas”. Será entre los años “2000 y 2003 cuando el resto de revistas femeninas de alta gama lanzan su versión digital” atendiendo a las características del internauta que se asemeja a la de "la nueva lectora de revistas femeninas online: público cada vez más joven, prácticamente equiparación de usuarios masculinos y femeninos en la red (56\% hombres y 44\% mujeres usuarias) clase media o media-alta, conexión desde el puesto de trabajo."

Pero, sin duda, entre todas estas publicaciones, los expertos destacan como un caso paradigmático y digno de estudio el caso de Vogue, revista de la editora multinacional Condé Nast International, considerada "una de las biblias de las revistas femeninas de moda de alta gama” tal y como se definía a esta publicación en una entrevista con su directora de la edición 
española también en 2013 con motivo de la celebración los veinticinco años de la revista en España, cuando se lanzó un número conmemorativo con más de 370 páginas y un despliegue inusitado en esos años de crisis (Sáez, 2013: 11).

\section{Objeto de estudio}

La revista Vogue nació en Estados Unidos como publicación semanal de la mano de Arthur Baldwin Turnure en el año 1892. La palabra "vogue" en francés e inglés puede ser traducida al castellano como "moda", "tendencia" o simplemente como "algo que está en boga”. Viene del francés “voguer" (navegar, remar). Su discurso genera todo un estilo de vida para sus lectoras (Elman, 2008) en una sociedad tan extravagante donde la distinción marca el criterio y las bases sociales del gusto (Bordieu, 1998). La moda expresa actitudes (Codina y Gatón, 2010: 193). Sin duda, desde sus orígenes la revista pretendía convertirse en la publicación de referencia de aquellos que querían estar a la última, en la onda, al corriente de las últimas tendencias. Tras la muerte de Arthur Baldwin en 1909, la editora entonces llamada solo Condé Nast, compró la revista y le dio un nuevo impulso y mayor difusión. En adelante, la revista tendría una periodicidad quincenal. Durante la década de 1910, Vogue ya se hace internacional y se empieza a editar en Gran Bretaña comenzando su difusión fuera de las fronteras estadounidenses, con diferentes resultados. Así llegó también a España donde fue un rotundo fracaso. La aventura hispana duró muy poco, pero en otros lugares como en Francia alcanzó rápidamente un gran número de ventas. Hoy en día, sus números antiguos son una excelente fuente documental para el estudio de la historia de la moda (Andrío Esteban, 2012: 44; Prieto Paíno y Sánchez García, 2015: 47).

\subsection{Vogue, la revista icono del sector de la moda}

A pesar de la crisis del 1929 y las dos guerras mundiales, Vogue siguió creciendo en número de venta de ejemplares, circulación, difusión e influencia social. En la década de 1960 y acorde con la ideología de la época, Vogue comienza a entrar en temas de debate sexual, tratando de atraer a los jóvenes. Durante esta época, la editora de la revista es Diana Vreeland, que se convertirá en una de sus editoras históricas y que marcará un antes y un después en la revista. Con Vreeland es la primera vez que el rol de la editora femenina empieza a jugar un fuerte rol social de honda influencia y calado en la sociedad del momento. A partir de los años sesenta, las portadas de Vogue las protagonizan personajes famosos, referentes de moda del momento, como Twiggy, Lauren Hutton, Veruschka, Suzy Parker o Marisa Berenson, entre otras (Watson, 1999). Con el cambio de década, en 1973, Vogue comienza a publicarse mensualmente. En ese momento, la editora jefe es Grace Mirabella, que renueva el estilo de la presentación, haciéndola más acorde con el estilo de vida del nuevo público.

Actualmente, la editora de la edición americana es la célebre Anna Wintour, periodista de origen británico pero nacionalizada estadounidense. Ocupa el puesto desde 1988 y ha llegado a convertirse en un auténtico ícono de la moda, tal y como lo hizo previamente en los años setenta su predecesora Diana Vreeland. En el caso de Wintour, además de ejercer su puesto 
como editora general de esa publicación, desde 2013 ocupa también el cargo de directora artística de todas las publicaciones del grupo editorial Condé Nast International. Desde su llegada en 1988, Wintour le ha dado nuevos aires a la revista, posicionándola en un lugar de liderazgo frente al resto. Las portadas ahora, en lugar de presentar la cara bonita de alguna famosa, ofrecen una imagen de tres cuartos, en la que la modelo pueda exhibir el torso, convirtiéndose éste en un mero escaparate para lucir joyas y prendas muy actuales. Incluso en ocasiones, combinan lo popular con la alta costura, como unos vaqueros de Mango con una camiseta de Carolina Herrera, presentada en algún desfile exclusivo. Otra faceta de esta nueva Vogue, es acoger a nuevos talentos. De esta manera, Wintour se ha convertido en una cazatalentos y en una referente de la industria textil. Su visión se hace ineludible a la hora de marcar tendencia.

Bajo las órdenes de Wintour, Vogue ha reorientado sus contenidos hacia los temas de moda, convirtiéndose en principal prescriptor y en un icono sobre el tema. Wintour, por su parte, se ha convertido en una auténtica "descubridora" de nuevas marcas que encajan potencialmente con las lectoras de su revista. La propia Anna Wintour se ha convertido ella misma en un personaje de revista y en una celebridad mundial, hasta llegar a inspirar la novela El diablo viste de Prada (Devil wears Prada, 2003) de la escritora estadounidense Lauren Weisberger y la posterior película del mismo título del año 2006 dirigida por David Frankel. En una entrevista con Angeletti y Oliva (2006: 251), la propia Anna Wintour afirmaba lo siguiente sobre Vogue:

"Es a la vez testimonio al mundo de la moda y su protagonista. Mostramos lo que vemos, sino que también ayudamos a crear lo que vemos. Cubrir los lanzamientos de las colecciones y tendencias de la moda es muy importante, pero lo que hacemos fuera de la revista es crucial: el apoyo a los nuevos talentos a través de la Fundación para la Moda de Vogue o trabajar en el Instituto del Traje del Museo Metropolitano de Arte escuchando a los minoristas, proporcionando divulgación de los espacios para los negocios y para los diseñadores, proporcionando toda una relación en varios niveles de la industria. Todo esto nos hace más que una revista. Somos una fuerza real en la moda. Para mí, esta parte vital de la vida de la revista es casi tan importante como lo que publicamos, ya que da apoyo a la moda de una manera que nadie más lo hace".

Hoy en día, Vogue no es solo una revista de moda que se publica en medio mundo, sino que transmite un estilo de vida a través de sus temas principales: la vida diaria, el diseño y obviamente la moda (Endres y Lueck, 1995: 417- 422). Desde el punto del vista de la fotografía, todos los grandes fotógrafos del mundo han publicados sus mejores instantáneas de moda en sus páginas (Guerrero González-Valerio, 2011: 31). Vogue ha contado con el trabajo de fotógrafos de prestigio mundial como Edward Steichen, Toni Frissell, Erwin Blumenfeld, Irving Penn, Richard Avedon, David Bailey, Helmut Newton, Annie Leibovitz, Mario Testino, Steven Klein, Bruce Webber y Herb Ritts, entre otros (Angeletti y Oliva, 2012) y de grandes editores de prensa especializados en moda como Suzy Menkes, Polly Mellen, Babs Simpson, Grace Coddington, Tonne Goodman, Camilla Nickerson y Phyllis Posnick (Macsweeney, 2012) por no hablar de las grandes modelos de todos los tiempos que han ocupado sus portadas, como Suzy Parker, Lisa Fossagrives, Jean Shrimpton, Linda Evangelista o Natalia 
Vodianova (Muir, 2016). Algunas de sus portadas son míticas, se han convertido en auténticos iconos de la moda y hasta se han editado en formato poster y postal para coleccionistas (Kazanjian y Bowles, 2011).

\subsection{La edición española de Vogue}

En la actualidad, Vogue es una publicación mensual que está presente en un total de 23 países. En diez países lo hace de manera directa con una publicación propia. Es el caso de Estados Unidos, donde nace, pero también cuenta con edición propia independiente en sus versiones de Reino Unido, Francia, Italia, Alemania, España, Japón, Taiwán, Rusia y México. Sin embargo, en otros trece países lo hace con la fórmula de "licencia" casi a modo de franquicia. Es el caso de las ediciones de Sudáfrica, Australia, Brasil, China, Corea, Grecia, Holanda, Hungría, India, Polonia, Portugal, Rumania y Suecia. Las revistas publicadas bajo esta licencia o permiso obedecen las reglas de la matriz central, la editorial Condé Nast International, especialmente en relación con cuestiones clave como son la clasificación de secciones, el número de páginas y el diseño gráfico.

Tras un fracaso inicial en los años veinte, el intento de publicar Vogue en España se retoma con la consolidación de la democracia en nuestro país después de la Transición. Hubo un intento de entrar en el mercado español en los primeros años ochenta, aunque sin éxito debido a las barreras legales vigentes todavía en ese período. Hasta el momento, tan solo Telva y Dunia, de capital nacional, competían en este sector. No fue hasta el mes de abril de 1988, cuando finalmente saliera a la luz en España una edición propia, con Luis Carta como su editor y Ana Puértolas como su directora, en un momento de gran concentración informativa en el sector (Cabello, 1999). Daba comienzo así lo que se ha llamado una “tercera generación de revistas femeninas” (Ganzabal Learreta, 2006: 410). Desde 1988, esta nueva edición de Vogue ya propone una mujer más activa, acorde a los nuevos tiempos, conforme a la propia tradición de la revista matriz, para entonces ya centenaria revista nacida en Norteamérica. La versión ibérica de Vogue tiene muchas cosas en común con la americana. Así, la versión española de Vogue también mantiene su pretensión elitista y de liderazgo tanto en calidad como en ventas así como en la clase social a la que se dirige, ya que sus lectoras potenciales deben ser de las capas más altas de la sociedad, tal y como escribió en su momento el propio editor, Luis Carta, según el testimonio recogido por Ganzabal Learreta:

"Somos elitistas y no nos dirigimos a cualquier mujer. La mujer Marie Claire o Elle son de clase media, trabaja pero no es directiva y en cierta forma aprende a vivir. La de Vogue tiene 30 años, si trabaja es directiva, sino tiene dinero por familia o por matrimonio, pero es una mujer abierta mentalmente, que si bien gusta de pequeños consejos no necesita que le expliquen como tener un orgasmo (...) La diferenciación vendrá dada por el precio y por el contenido. Vogue sale a la calle al precio de 350 pesetas y un vestido de Vogue deberá costar por lo menos diez veces más que uno de Marie Claire" (Ganzabal Learreta, 2006: 409) 
De esta manera tan directa se presentaba Vogue en el mercado español en 1988. El mercado de la prensa femenina en España es muy dinámico, por lo que la competencia es tal que cada publicación no ha dejado de renovarse continuamente. El hecho de que Vogue sea de origen extranjero y pertenezca a un gran grupo multinacional no la hace indemne a este competitivo escenario español. Muy por el contrario, la revista rápidamente se fue transformando y evolucionando de la mano de sus directoras. Así, en 1997 redujo su formato y se quedó con la que sigue siendo hoy su directora, Yolanda Sacristán. En 2002, el grupo Condé Nast International completaría su oferta en el mercado español con el lanzamiento de la revista Glamour, con un formato reducido y liderando las ventas de las femeninas, con lo que se introduce en nuestro país lo que algunos llaman la "cuarta generación de revistas femeninas". Sin embargo, el gran salto vendría con su adaptación a la revolución digital.

\section{Metodología: variables para el análisis al salto digital}

Este trabajo arranca del siguiente punto de partida a modo de hipótesis. A medida que el mercado de lujo ha crecido, éste se ha ido enfrentado a diferentes retos. Uno de los principales ha sido la aparición de Internet como forma de democratización y divulgación de la información y del conocimiento.

En este contexto, surge una pregunta de investigación. ¿̇s Internet un enemigo, una amenaza o una oportunidad para las revistas de lujo como Vogue y todo el universo simbólico del negocio del lujo que la revista representa? Aunque Internet supone una excelente oportunidad para el lanzamiento y construcción de marcas, es un medio de acceso global, cuya difusión amplia pondría en peligro conceptos sustanciales de lujo, como son la tradición, la rareza y la exclusividad.

Este trabajo defiende la siguiente tesis: Internet es una excelente oportunidad para las marcas de lujo para construir relaciones más estrechas y personalizadas con sus consumidores. El sector del lujo, en el que se incluye Vogue, es una industria capaz de reinventarse a sí misma, aliarse con Internet, adaptarse, sobrevivir y triunfar en los revueltos tiempos de la revolución digital y además es capaz de generar y desarrollar nuevos hábitos asociados a ciertas actitudes y prácticas de las tendencias socio-culturales exclusivas de su sector. De este modo, este trabajo asume como objetivo principal el análisis de la web de la revista Vogue en su edición española para tratar de explicar la evolución de medio impreso de lujo a publicación digital de libre acceso. ¿Qué tienen en común y en qué se diferencian las versiones en papel y online? ¿Cuáles son sus contenidos? ¿Y su(s) estilo(s)? Para ello se proponen en este trabajo el estudio de las siguientes variables:

1) Audiencia en España de acuerdo con la Oficina de Justificación de la Difusión (OJD) y del Estudio General de Medios (EGM) tanto en su perfil cualitativo como cuantitativo.

2) Secciones principales de las que se compone.

3) Estructura visual, horizontal o vertical, colores principales, predominio de la imagen o del texto 
5) Formatos publicitarios, según las tarifas oficiales de publicidad

6) Mecanismos de promoción de la revistas en redes sociales (con especial atención a Facebook, Twitter e Instagram)

7) Distribución de los contenidos principales (especialmente a través del binomio moda y belleza). Esta variable será analizada en función del número de temas abiertos en los foros de Vogue.es y en función de la amplitud de cada sección en la web.

8) Interactividad con las lectoras, entre las que destaca el número de posts, respuestas y otras formas de interactividad, siguiendo otros trabajos como los de Hinojosa-Mellado (2008: 726-734). Este parámetro será analizado, por un lado, en función de los foros de la web, y por otro, en función de los comentarios obtenidos por los posts de la editora internacional Suzy Menkes, en el primer scroll de su sección.

9) Brand placement (cómo aparecen las marcas). ¿¿Se produce de un modo integrado o manifiesto? Aquí se analizarán cómo aparecen las marcas en la portada de la revista, así como en las portadillas de las secciones de moda y belleza. Será integrado cuando no se muestre ningún tipo de marcador ortotipográfico (negritas, cursiva, subrayado) ni exista un apoyo audiovisual (imagen o video). Será manifiesto cuando sí que utilice dichos marcadores o llamadas de atención, conforme a la clasificación metodológica propuesta por Cristófol y Méndiz (2015: 14).

\section{Análisis y resultados}

Según datos propios de Condé Nast International (disponibles en www.vogue.es), la edad media de las lectoras de Vogue es de 38,5 años, con unos ingresos medios de 60.000 dólares/54.000 euros anuales, un 87,5\% son mujeres y un $66 \%$ de las mismas tienen educación superior. En los estudios previos sobre la revista, como el realizado sobre los contenidos por Ganzabal Learreta (2006), se afirma que los temas principales de la revista online se reparten conforme a la siguiente proporción: moda $52 \%$, belleza $6 \%$, publicidad $35 \%$, otros contenidos $7 \%$. Por su parte, la edición en papel cuenta con más contenidos. Las ediciones impresas se componen de las siguientes secciones: moda (general, estación, accesorios), novedades, gente y actualidad, belleza (cuerpo, tendencias, cosmética, cabello y perfume), reportajes y encuentros y living. El peso y proporción de las secciones es cambiante. Del estudio de las nueve variables propuestas anteriormente, se desprenden los siguientes datos:

1) Audiencia. Desde el punto de vista cuantitativo, la versión impresa de Vogue en España tiene una difusión de 88.532 ejemplares según la OJD (http://www.ojdinteractiva.es/muestra_acta/medios-digitales/851/02/2015/). La revista en papel cuenta con 944.000 lectoras según el EGM. Sin embargo, a través de su web, la revista llega a 3.740 .405 usua- 
rios únicos con 47.594 .869 páginas vistas (según Google Analytics) de acuerdo con los datos publicados en http:// cnworld.es/ consultados el 23 de marzo de 2015. De acuerdo con los datos de informe de Introl sobre la web www.vogue.es para ese mismo período, la revista online contaba con un total de 4728.367 visitas, a través de 2.688.488 navegadores únicos y 43.609.588 páginas vistas. Eso hace un promedio diario de 168.870 visitas, 1.587 .484 páginas diarias vistas y un acceso de 139.417 navegadores nuevos al día. Es decir, la web tiene una media de 9,19 páginas vista por usuario, con una duración de 4,15 minutos, es decir, 31 segundos por página. Desde el punto de vista cualitativo, según un estudio llevado a cabo en 2009 por la consultoría de investigación de mercados The Cocktail Analysis por encargo del grupo Condé Nast International con lectoras habituales de revistas, la seguidora de Vogue estima que se trata de una "revista aspiracional, icono de estilo y garantía de marca" y cuya "publicidad es igual de importante que su contenido" convirtiéndose en un "referente en nuevas tendencias de moda". Con respecto a su publicidad y según dicho informe, en ella "se anuncian marcas más lujosas y prestigiosas, los anuncios son más cuidados así como el tipo de marca que se anuncia y la publicidad es casi tan importante como el contenido.”

2) Secciones. Las principales secciones con las que cuenta la edición online de Vogue en España son ocho y se dividen del siguiente modo:

a) Moda, cuyas subsecciones son a su vez News (reúne las principales noticias del sector), Tendencias (de las marcas y celebrities), Streetstyle (la moda en la calle), Modapedia (una guía con los principales gurús del sector: diseñadores, marcas, fotógrafos, modelos, personajes, estilistas e hitos), Espía (recoge los principales eventos y noticias de las marcas de moda), Dress for less (tendencias a bajo coste) y Jobs (donde se publicar ofertas de trabajo del sector de la moda).

b) Belleza, no incluye subsecciones específicas, pero trata temas desde el maquillaje, hasta las operaciones estéticas y en ocasiones temas de salud.

c) Pasarelas, se compone a su vez de secciones como París Fashion Week (o la pasarela más cercana en el tiempo), temporadas, diseñadores (guía de tendencias por diseñador) y la sección genérica fashion weeks (resumen de los principales acontecimientos y desfiles de las últimas pasarelas de cada país).

d) Suzy Menkes, prestigiosa periodista de moda y editora internacional de Vogue, describe y opina sobre el sector desde su personal punto de vista al tiempo que muestra su agenda y vida social por todo el mundo.

e) Celebrities reúne las principales tendencias de la sociedad internacional en su día a día o en eventos de repercusión mundial

f) Novias, se estructura en pasarela, tendencias (con las principales noticias de las marcas) y agenda (con ideas y sugerencias para que la boda sea lo más diferente al resto posible) 
g) Televisión (TV), sección contenedora de los principales vídeos de Vogue. Se subdivide en apartados diversos sobre moda, pasarelas, belleza, galas, confidencial y actualidad (de las marcas).

h) Blogs de reconocidas periodistas o personales del sector como Blanca Suárez, Clara Alonso, Blanca Galocha, Cameron (El diablo se vista de Zara), el blog titulado Casilda se casa, o el bitácora de Mónica Parga.

3) Estructura. Respecto a la estructura visual (horizontal/vertical) y el uso de los colores principales, es preciso decir que la web se estructura horizontalmente y los colores principales son el blanco y el negro, existiendo un claro predominio de la imagen por encima del texto, siguiendo la tendencia de la edición impresa.

4) Presencia de las editoras. La editora internacional Suzy Menkes tiene su sección específica, pero en el caso de España, destaca el hecho de la propia directora Yolanda Sacristán, con casi 20 años al frente de la dirección de la revista, no tenga ninguna sección específica, aunque es tratada por su propia revista como un personaje que marca tendencias, estudiando cada uno de sus looks en los reportajes en los que se muestran fotos en la directora en eventos especiales a los que acude o bien ella misma organiza en su calidad de responsable de la edición española de Vogue, o bien en las entrevistas que realiza en su calidad de directora y que van acompañadas de reportaje gráfico.

5) Formatos publicitarios. En las tarifas oficiales publicadas la edición online de Vogue ofrece los siguientes formatos. Por un lado, en la lectura en rotación (o scroll) existe la posibilidad del anuncio a través de las siguientes fórmulas: megabanner, megabanner desplegable, robapáginas, robapáginas desplegable, skyscrapper y skyscrapper desplegable. Por su parte, en la sección de foros y chats, se da la posibilidad de megabanner estándar o video, robapáginas estándar o skyscrapper. También se recogen algunos formatos especiales como son las fórmulas de takeover fullscreen, hockeystick, pushdown sidekicky billboard. La revista digital también ofrece la posibilidad de incluir publicidad en las campañas de correo electrónico o emailing a través de las acciones de marketing de la revista, es decir, existe la posibilidad de patrocinar una newsletter $\mathrm{u}$ otro tipo de contenidos u opciones especiales.

6) Mecanismos de promoción en redes sociales. La versión española de Vogue cuenta con perfiles propios consolidados en los principales social media como son Facebook (https://www.facebook.com/VogueEspana), Twitter (@VogueSpain) e Instagram (https://instagram.com/voguespain), así como un canal en Youtube (https://www.youtube.com/user/VogueEspana). En Facebook, según los datos del estudio efectuado el 23 de marzo de 2015, un total de 85.990 personas hablaron ese día de la revista, con un total de 1.601.679 "Me gusta", lo que representa un incremento total del $0,3 \%$, es decir, 5.491, un 6,4\% menos que la semana anterior. Con respecto a la información que nos proporciona en su perfil, se presenta como la página oficial de la revista Vogue en España en Facebook y nos incita a seguirle en Twitter a través de @VogueSpain o en www.vogue.es. El perfil se presenta con la fecha de nacimiento de la edición en papel (01/abril/1988) y nos ofrece como correo de contacto, un formulario online. Publica ante 
todo fotos, contando exclusivamente con tres vídeos colgados a disposición de sus seguidores en Facebook. En su sección "Suscríbete", aparece una promoción conjunta para Vogue convencional y su aplicación de iPad con un precio especial. El perfil de la revista en Twitter nace en abril de 2009 y tiene un total de 21.600 de tweets publicados, de los cuáles 14.900 contienen fotos o vídeos. Sigue a un total de 354 personas y cuenta con 957.000 seguidores. Tiene 38 posts marcados como favoritos y ocho listas creadas. Por lo que respecta al perfil de la revista en la red social Instagram, la revista Vogue tiene publicadas un total de 1.181 fotografías. Cuenta con 313.000 seguidores y sigue a 272 usuarios de esta red social. Finalmente, respecto a Youtube, el canal de la revista de moda cuenta con un total de 4829 seguidores.

7) Distribución de los contenidos. Si analizamos los foros creados, vemos que se abren tres grandes bloques llamados 'Administración', 'Foros de Vogue.es' y 'Debate Abierto'. En el caso del foro 'Administración' se trata de un espacio también denominado 'Tablón de anuncios, normas y contacto con administración'. Cuenta con un total de 617 temas y 7308 mensajes. Es descrito como "todo lo que debes saber de anuncios, comunicados y normas por parte de la dirección de Vogue.es además de propuestas de los usuarios de estos foros a los administradores”, tal y como se afirma en la propia web de la revista. Respecto a los 'Foros de Vogue.es' el usuario se encontrará con diferentes subtemas siempre ligados a cuestiones puntuales de moda, celebrities, belleza, pasarelas, novias, decoración, gourmet, viajes, Mamás Vogue, trabajo y estudio, y finalmente salud. Los temas y mensajes que nos encontramos en cada caso son los que se muestran a continuación en este gráfico: 
Tabla 1. Listado de contenidos

\begin{tabular}{|l|l|c|c|}
\hline Sección & Descripción & Temas & Mensajes \\
\hline Moda & $\begin{array}{l}\text { La moda práctica para todos. Qué llevo hoy, en qué tienda puedo encontrar esas botas } \\
\text { maravillosas, cómo puedo conseguir aquel look }\end{array}$ & 38588 & 2287428 \\
\hline Celebrities & Ofrece tu opinión acerca de los últimos acontecimientos en el mundo del glamour & 11952 & 3291155 \\
\hline Belleza & $\begin{array}{l}\text { Comparte con nosotros tus mejores trucos y sugerencias para mostrar siempre la } \\
\text { mejor cara }\end{array}$ & 30508 & 2179465 \\
\hline Pasarelas & $\begin{array}{l}\text { Este es tu espacio para que comentes lo que quieras sobre las últimas pasarelas. iQué } \\
\text { diseñador te ha gustado? ¿Qué desfile te ha sorprendido? }\end{array}$ & 1678 & 362491 \\
\hline Novias & Danos todas tus sugerencias para hacer del día de tu boda el más especial de tu vida & 3478 & 294005 \\
\hline Decoración & Comparte tus ideas para decorar. iLa moda también en casa! & 2071 & 46372 \\
\hline Gourmet & $\begin{array}{l}\text { El foro para hablar de restaurantes, delicatesen, vinos,... Además comparte tus platos } \\
\text { más suculentos y tus recetas secretas }\end{array}$ & 2474 & 134948 \\
\hline Viajes & ¿Te gustaría conocer los mejores rincones del planeta? & 3720 & 48088 \\
\hline $\begin{array}{l}\text { Mamás } \\
\text { Vogue }\end{array}$ & $\begin{array}{l}\text { Consejos para estar más guapas durante el embarazo, experiencias de madres prime- } \\
\text { rizas, cuidados para ti y tu bebé }\end{array}$ & 4648 & 261082 \\
\hline $\begin{array}{l}\text { Trabajo y } \\
\text { Estudio }\end{array}$ & $\begin{array}{l}\text { Porque nos pasamos la vida estudiando o trabajando. Opina sobre empresas, acade- } \\
\text { mias, cuéntanos experiencias estudiantiles o laborales y ofertas de empleo. }\end{array}$ & 3461 & 96714 \\
\hline Salud & $\begin{array}{l}\text { Aquí puedes hablar de todo lo que te preocupa sobre tu salud y compartirlo con los } \\
\text { demás }\end{array}$ & 1857 & 100600 \\
\hline
\end{tabular}

Fuente: Elaboración propia.

Los temas propuestos sobre moda representan un $37 \%$ del total y los de belleza un $29 \%$. Con respecto a la web, se observa que frente a las ya citadas siete secciones en la que se subdivide el apartado moda, belleza no cuenta con ninguna. Además, contabilizando en número de noticias en portada de cada tema aparecen diez de moda, frente a tres de belleza, una sobre celebrities, una de VogueTV, tres de novias, una de Living, los seis blogs, y la pasarela de alta costura verano 2015.Por lo que parece que el binomio moda y belleza, no es tal en esta revista. 
Gráfico 1. Temas de debate

\section{NÚMERO DE TEMAS ABIERTOS EN CADA UNA \\ DE LAS SECCIONES PROPUESTASEN LOS \\ FOROS DE VOGUE.ES}

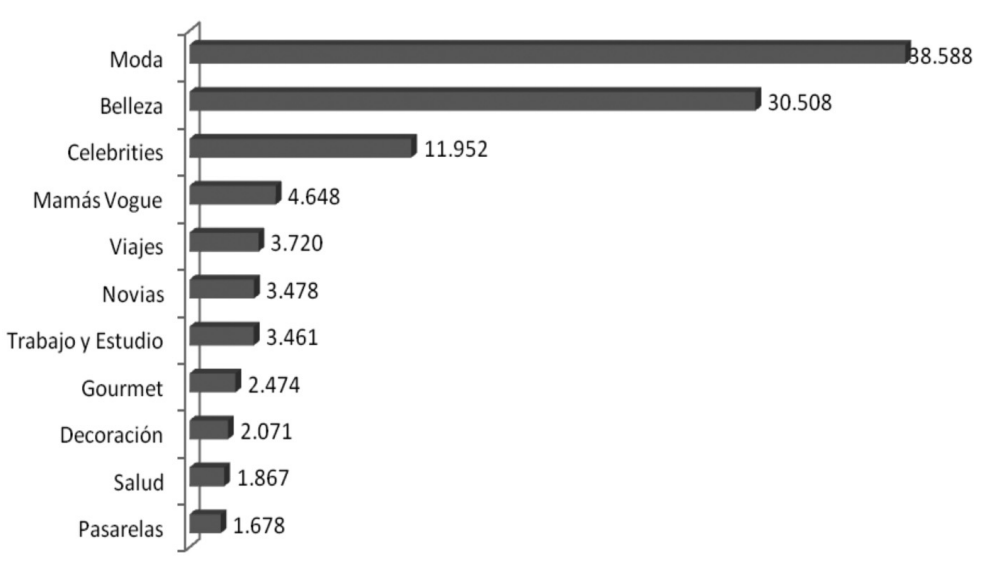

Fuente: Elaboración propia.

Finalmente, en la tercera sección, llamada 'Debate Abierto', es posible encontrar a su vez diferentes subsecciones, casi todas ellas de temática cultural. Se trata de 'Tu Mundo', 'Ocio y Cultura' sobre cine, libros, música y televisión, y por último un apartado para 'Las presentaciones de los nuevos foreros' en las que los nuevos usuarios se pueden dar a conocer.

Tabla 2. Participación en foros

\begin{tabular}{|l|l|c|c|}
\hline Sección & Descripción & Temas & Mensajes \\
\hline Tu Mundo & $\begin{array}{l}\text { Experiencias, vivencias, amistados, amor,... Tu mundo pleno de acti- } \\
\text { vidades, cargado de sentimientos. ¡Compártelo! }\end{array}$ & 34798 & 3275462 \\
\hline Ocio y Cultura & $\begin{array}{l}\text { Aquí todo lo que te apetezca comentar de cómo pasas tu tiempo } \\
\text { libre, nuevas películas, presentaciones, libros, ... }\end{array}$ & 4016 & 1833739 \\
\hline $\begin{array}{l}\text { Las presentaciones de los } \\
\text { nuevos foreros }\end{array}$ & $\begin{array}{l}\text { Preséntate aquí para que todos te conozcamos. Cuéntanos qué te } \\
\text { gusta, tus pasiones, tus ideas,... }\end{array}$ & 3422 & 13956 \\
\hline
\end{tabular}

Fuente: Elaboración propia. 
8) Interactividad con las lectoras. En su conjunto, todos los foros de la versión digital de Vogue cuentan con un total de 14.247.969 mensajes totales, 150.733 temas totales y 124.988 usuarios totales, por lo que se establece una media de 114 mensajes por cada uno de los usuarios y de 95 mensajes por tema. Si desglosamos el número de mensajes recibidos en cada apartado de los foros propuestos, obtendríamos el siguiente ranking de temas de interés:

Gráfico 2. Mensajes de los foros

\section{NÚMERO DE MENSAJES RECIBIDOS EN CADA UNO DE LOS FOROS}

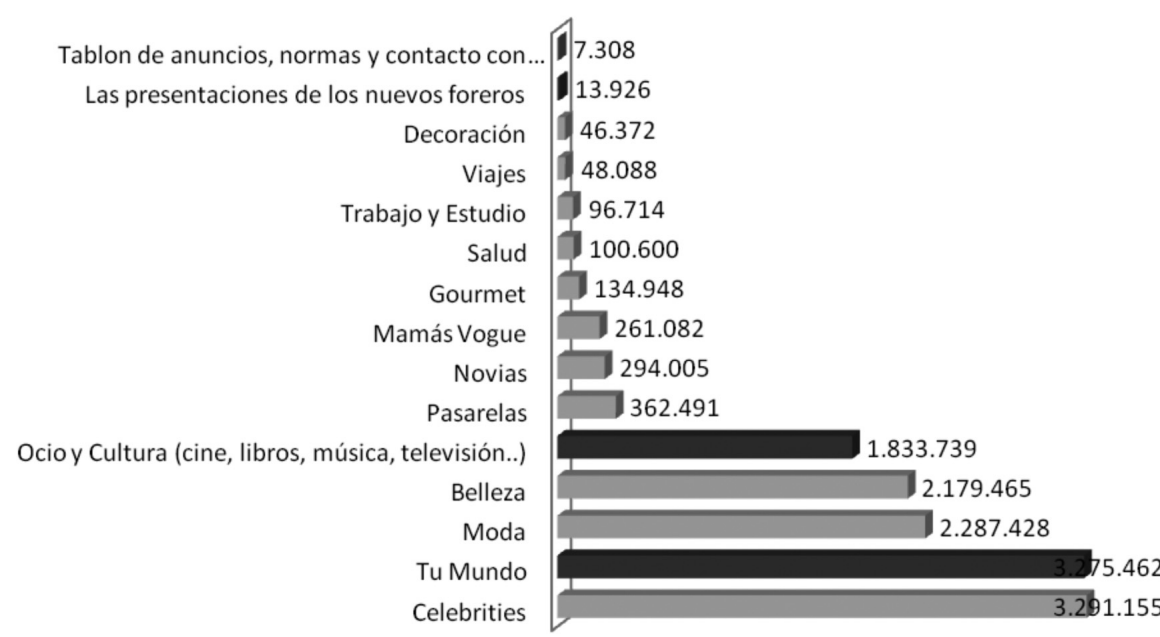

Fuente: Elaboración propia.

Por otro lado, analizando los posts del blog de la editora internacional de estilo, la americana Suzy Menkes, que aparecen en el primer scroll, vemos el siguiente tipo de interacción a través de las redes sociales de Facebook y Twitter. 
Tabla 3. Interacción en redes sociales

\begin{tabular}{|l|c|c|}
\hline Título & Compartido en Facebook & Compartido en Twitter \\
\hline El zapato de plumas de pavo real picotea al bolso sencillo & 15 & 73 \\
\hline Alexander McQueen: exposición Savage Beauty & 28 & 160 \\
\hline Rahul Mishra: el canto del ave & 5 & 22 \\
\hline Alexander McQueen: belleza salvaje más que nunca & 74 & - \\
\hline Iris Van Herpen: 'Hacking Infinity’ & 85 \\
\hline Moncler Gamme Rouge: La emoción de la caza & 16 & 59 \\
\hline Miu Miu: Todo cubierto & 13 & 50 \\
\hline Valentin Yudashkin: un bosque ruso & 13 & 53 \\
\hline Totales & 172 & 502 \\
\hline
\end{tabular}

Fuente: Elaboración propia.

Como consecuencia de esta tabla sobre los comentarios Suzy Menkes, se puede afirmar que la red social de Facebook se comparte cada post una media de 21 veces mientras que en el caso de Twitter este promedio se eleva a 63.

9) Brand placement. Todas las marcas observadas en las diferentes secciones llevan fotografía de algún producto de la marca mencionada. En portada todas las que aparecen son del sector de la moda, no hay ninguna de belleza. Se observa en diversas ocasiones como las fotografías muestran a las modelos con prendas que incluyen el logotipo de la marca (un ejemplo muy evidente de este caso, ocurre con Louis Vuitton). Si nos adentramos en las dos secciones principales, volvemos a observar la misma tendencia: nada de brand placement de belleza y sin embargo, de manera exhaustiva en moda. De hecho, puede observarse, igual que en general en todos los medios impresos casi siempre "existen secciones cuya única finalidad es comercial" (Cristófol Rodríguez y Méndiz Noguero, 2015: 23). En el medio digital, las secciones Modapedia, Espía, StreetStyle, DressForLess o Jobs dan pie a la inclusión de marcas de forma evidente. De este modo, "los contenidos informativos, en los que de forma natural tienen presencia las marcas comerciales, resultarían forzados sin esas marcas, ya que se tiende cada vez más a representar la realidad, y no procede olvidarse de las marcas, puesto que forman parte de nuestra vida” según Cristófol Rodríguez y Méndiz Noguero (2015: 23)

\section{Discusión y conclusiones}

A medida que el escenario al que se enfrentaba el mercado de las revistas sobre moda, belleza, estilo y tendencias ha crecido, son muchos los retos que han surgido ante él, siendo la aparición y popularización en el uso de Internet

$70 \mid n^{\circ} 24$, pp. 55-75 | doxa.comunicación 
probablemente el más importante. Internet se presentaba en un principio como una gran amenaza, como el enemigo que podía poner fin a las revistas de esta gama, ya que era un medio de acceso global, cuya difusión amplia pondría poner en peligro conceptos sustanciales de este tipo de publicaciones como eran el lujo, la tradición, la rareza e incluso la exclusividad. Se pueden extraer estas conclusiones generales:

1) Sin embargo, Internet se ha convertido en el gran aliado de las publicaciones sobre moda y belleza porque se ha demostrado que gracias al poder de las redes sociales es una excelente herramienta y oportunidad para generar y construir marcas asociadas a valores. En este sentido, desde la popularización de Internet, la revolución digital se ha convertido en un caldo de cultivo favorable para el lucrativo negocio de las publicaciones de moda y belleza, incluidas aquellas consideradas de alta gama, como es el caso de Vogue. Internet ha demostrado ser una excelente oportunidad para las marcas de lujo para construir relaciones más estrechas y personalizadas con sus consumidores. El mercado de las publicaciones de lujo ha demostrado ser una industria capaz de reinventarse a sí misma e interpretar diferentes roles y funciones sociales a través del tiempo, asociados a ciertas actitudes y prácticas de las tendencias socio-culturales más punteras.

2) Como podía intuirse desde un principio, la edición digital de la revista ha ampliado el número de seguidoras de la misma, modificando tanto su perfil socio-demográfico (en Internet son más jóvenes) como la media de tiempo que cada una emplea para su lectura: mientras que para la edición impresa, el tiempo es ilimitado y puede consultarse cuántas veces quiera la lectora, en la edición digital, el tiempo medio de lectura es de tan solo treinta segundos. Lo que está claro es que, frente a la lectura reposada de la edición impresa, dedicada principalmente al análisis de tendencias, revistas en profundidad y reportajes fotográficos, la edición digital, tiene una lectura mucho más ágil, en la que se busca más el titular que el análisis.

En el apartado de conclusiones específicas cabría subrayar los siguientes puntos relativos al análisis de la versión digital de la edición española de Vogue:

1) En relación a las principales secciones de las que se ocupa cada una de las ediciones, la revista impresa es mucho más amplia que la digital, cuyos contenidos se centran, como hemos podido observar en moda y belleza exclusivamente, temas tratados en menor profundidad y de forma más dinámica. Con respecto a la estructura visual, bien es cierto que la edición online predominan los colores clásicos y elegantes como son el blanco y el negro, aportando la elegancia y los valores que se le presuponen a la marca Vogue. Predomina la imagen sobre el texto, igual que en la edición impresa. Al contrario que en la edición de papel, en la que la editora española ocupa un lugar predominante, haciendo el editorial mensual, en la edición online, es la editora internacional la que ocupa un lugar destacado, creando un blog sobre moda. 
2) La publicidad se sigue cuidando y los formatos son muchos más en la edición digital, gracias a el formato audiovisual y los hipervínculos. Sin embargo, para dar a conocer productos con muestras (maquillajes, perfumes, cremas...) o encartar catálogos, en la Vogue impresa la lectora se muestra mucho más receptiva, ya que en la edición online precisa aportar datos a la marca que le va a suministrar el producto.

3) Gracias a las redes sociales, la revista ha conseguido mucha más notoriedad, y es evidente que gracias a ellas ha conseguido ampliar el número de seguidoras. Facebook sigue siendo la red social en la que mayor número de seguidores tiene, dado que esta red está más extendida en nuestro país que el resto y que se creó la primera de las que utiliza la revista; con Twitter, se permiten un gran número de actualizaciones, aunque el número de seguidores es mucho menor; Instagram sin embargo está creciendo de forma vertiginosa, gracias a su capacidad de comunicar con imágenes. Por este motivo se convierte en una herramienta esencial para la promoción de la revista, en la que predomina la imagen. Es curioso observar que, a pesar de tener un canal específico en Youtube y un apartado de Vogue TV, casi no se comparten estos contenidos audiovisuales. La interactividad con las usuarias también se ha visto reforzada con la edición online, gracias a las redes y a los foros, donde es evidente que los temas que más demanda suscitan son moda, belleza y celebrities en ese orden si nos atenemos al número de temas abiertos, o celebrities, moda y belleza, si nos atenemos al número de mensajes recibidos. Es posible comprender gracias a esto que los principales contenidos en digital sean estos mismos, y no los amplíen a otros como en la edición impresa.

4) Finalmente, respecto al brand placement, es evidente que en internet mucho más que en papel, la inclusión de marcas es necesaria para dotar de realismo y credibilidad a los contenidos, por lo que no solo se mencionan marcas, sino que en todas las ocasiones, dicha mención dirige a un hipervínculo con la web de la misma.

En general, como principales conclusiones, por tanto, puede observarse como la edición digital, no ha hecho más que ampliar a la de papel dotando a la publicación de nuevas lectoras, mayor dinamismo en los temas de moda y belleza y mucha más participación por parte de las lectoras de la revista, acercando la publicación además a públicos más jóvenes, ampliado el mercado en estos tiempos de crisis.

\section{Bibliografía, fuentes y referencias}

Aguilera Moyano, M. (2014): “Cambian las comunicaciones, cambian los conceptos con los que entenderlas. Necesidad de nuevas categorías”, Telos, n. 98, pp. 01-03.

Alanís Muñoz, L., Cabezuelo Lorenzo, F. y Fanjul Peyró, C. (2015): “Las nuevas blogueras de moda como paradigma de la nueva comunicación digital especializada”, en Carrillo, V., Fernández, P. y Parada, J. L. (Coords.): Las gestión de intangibles para la excelencia empresarial: nuevas oportunidades para la comunicación y sus profesionales. Valencia: Foro de la Comunicación-Camp Gràphic, pp. 308-319. 
Andrío Esteban, M. R. (2012): “La máquina del tiempo de la moda: el archivo Vogue". Archivamos: Boletín ACAL, n. 83, pp. 44-45.

Angeletti, N. y Oliva, A. (2012): In Vogue. The Illustrated History of the World's Most Famous Fashion Magazine. New York: Rizzoli.

Bauman, Z. (2010): Mundo-consumo. Barcelona: Paidós.

Bourdieu, P. (1998): La distinción. Criterio y bases sociales del gusto. Taurus, Madrid.

Buitoni, D. (1990): Imprensa Feminina. São Paulo: Atica.

Cabello, F. (1999): El mercado de revistas en España: concentración informativa. Barcelona: Editorial Ariel

Cabezuelo Lorenzo, F. (2013): “Cinco años de crisis en el mercado de la comunicación (2008-2013)”, Historia y Comunicación Social, n. 18, pp. 703-715. (DOI:10.5209/rev_HICS.2013.v18.44358).

Codina, M. y Gatón, M. (2010): “La moda como una nueva actitud. Tyme Style and Design Magazine: 2005-2009”, Doxa Comunicación, n. 3, pp. 193-202.

Costa Sánchez, C. y Piñeiro Otero, T. (2013): Estrategias de comunicación multimedia. Barcelona: Editorial UOC.

Cristófol Rodríguez, C. y Méndiz Noguero, A. (2015): “Análisis del brand placement en las revistas femeninas. Hibridación de discursos: informativo, publicitario y de la moda". Revista Mediterránea de Comunicación: Mediterranean Journal of Communication, n. 6 (1), pp. 7-25.

Díaz Noci, J. (2010): "Medios de comunicación en Internet: algunas tendencias”. El profesional de la información, noviembre-diciembre, v. 19, n. 6, pp. 561-567

EAE Business School (2015): “Crece el mercado textil español hasta superar los 23.600 millones de facturación”. Disponible en: http://www.eae.es/news/2015/10/05/crece-el-mercado-textil-espanol-hasta-superar-los-26.600-millones-de-facturacion (Consulta: 25 de agosto de 2016).

El Publicista (2013): "Yolanda Sacristán, directora de la edición española de Vogue: "Vivimos una de las épocas más fructíferas de la revista”, El Publicista. Noticias de la publicidad, la comunicación y el marketing, n. 292, pp. 20-23.

Elman, D. (2008): Jornalismo e estilos de vida: o discurso da revista Vogue. Tesina de postgrado. Universidade Federal do Rio Grade do Sul (Brasil).

Endres, K. L. y Lueck, T. L. [Eds.] (1995): Women's periodicals in the United States: consumer magazines. New York: Greenwood Publishing Group.

Fernández del Moral, J. [Coord.] (2004): Periodismo Especializado. Barcelona: Editorial Ariel.

Foucault, M. (1989): Vigilar y castigar. Buenos Aires: Siglo XXI.

Gallego Ayala, J. (1990): Mujeres de papel: De ;Hola! A Vogue: la prensa femenina en la actualidad. Barcelona: Icaria. 
Ganzabal Learreta, M. (2006): "Nacimiento, remodelación y crisis de la prensa femenina contemporánea en España”, Revista Latina de Comunicación Social, n. 61, pp. 15.

Ganzabal, M. (2007): "La inevitable presencia de las revistas femeninas de alta gama en la red". Presencia y futuro de la comunicación digital. (Coords José J. Verón y Fernando Sabés), pp. 69-80.

García López, J. (2016): Dispublicitados. Murcia: Editum.

González Díez, L. y Pérez Cuadrado, P. (2009): "La Moda Elegante Ilustrada y el Correo de las Damas, dos publicaciones especializadas en moda en el siglo XIX”. Doxa Comunicación: revista interdisciplinar de estudios de comunicación y ciencias sociales, n. 8, pp. 53-72.

González Díez, L. (2011): "Los suplementos dirigidos a la mujer en la prensa diaria española: Mujer Hoy, Yo Dona y S-Moda” en Pérez Cuadrado, P. y Puebla Martínez, B. [Coords.]: Revistas versus magazines. Madrid: Universidad Rey Juan Carlos, pp. $15-30$.

Guerrero González-Valerio, B. (2011): “La evolución de Vogue a través de cuatro de sus grandes fotógrafos”, en Pérez Cuadrado, P. y Puebla Martínez, B. [Coords.]: Revistas versus magazines. Madrid: Universidad Rey Juan Carlos, pp. 31-38.

Guiry, M., Magi, A. W. y Lutz, R. J. (2006): “Defining and measuring recreational shopper identity”. Journal of the Academy of Marketing Sciences, v. 34, n. 1, pp. 74-83.

Hinojosa-Mellado, M. P. (2008): "Análisis de un post de moda en la versión digital de Vogue" en Pérez-Amat García, R., Núñez Puente, S. y García Jiménez, A. [Coords.]: Comunicación, identidad y género (2). Madrid: Editorial Fragua, pp. 726734.

Johnson, K. K. P., Schofield, N. y Yurchisin, J. (2002): "Appearance as a source of information: a qualitative approach to data collection". Clothing and Textiles Research Journal, v. 20 n. 3, pp. 125-137.

Kang, M., Sklar, M. y Johnson, K. K. P. (2011): “Men at work: using dress to communicate identities”, Journal of Fashion Marketing and Management, Vol. 15, n. 4 pp. 412-427.

Kawamura, Y. (2005): Fashionology: An Introduction to Fashion Studies. Oxford: Berg Ltd.

Kazanjian, D. y Bowles, H. (2011): Vogue: The Covers. New York: Abram Books.

Macsweeney, E. (2012): Vogue: the editor's eye. New York: Condé Nast.

Muir, R. (2016): Vogue 100: A Century of Style. New York, Abrams Books.

Peluchette, J. V., Karl, K. y Rust, K. (2006): “Dressing to impress: beliefs and attitudes regarding workplace attire”. Journal of Business and Psychology, n. 21, pp. 45-63.

Prieto Paíno, C. y Sánchez García, P. (2015): “Archivos con estilo: Vogue celebra su 95º aniversario”. Archivamos: Boletín $A C A L$, n. 98, pp. 47-50. 
Riera, M. (2015): “¿Cómo diseñar moda con técnicas de Big Data?” Disponible en: http://piperlab.es/como-disenar-modacon-tecnicas-de-big-data/ (Consulta: 6 de agosto de 2016)

Roach-Higgins, M. E. y Eicher, J.B. (1992): “Dress and identity”, Clothing and Textiles Research Journal, v. 10 n. 1, pp. 19-45.

Rueda Laffond, J. C., Galán Fajardo, E. y Rubio Moraga, Á. L. (2014): Historia de los medios de comunicación. Madrid: Alianza Editorial, pp. 208.

Sáez, M. (2013): "Yolanda Sacristán, directora de Vogue España, habla del $25^{\circ}$ aniversario de la revista”. Anuncios. Semanario de publicidad y marketing, n. 1457, pp. 11.

Smith, N. (2012): Clothing and the Communication of Culture: The Sociology of Fashion. Disponible en: http://www.articlemyriad.com/clothing-communication-culture-sociology-fashion/ (Consultado el 25 de agosto de 2016).

Stryker, S. y Burke, P. J. (2000): “The past, present and future of an identity theory”, Social Psychology Quarterly, v. 63, n. 4, pp. 284-97.

The Cocktail Analysis (2009). "Informe Ediciones Condé Nast: del compromiso a la decisión de compra". Disponible en http://cnworld.es/pdf/estudio2009.pdf (Consultado el 25 de agosto de 2016).

Watson, L. (1999): Vogue. Twentieth Century Fashion, 100 Years of Style by Decade and Designer. London: Carlton Books. 